$4^{\text {th }}$ International Meeting on Calcitonin Gene-Related Peptide (CGRP)

TheScientificWorld (2001) 1(S1), 35

ISSN 1532-2246; DOI 10.1100/tsw.2001.424

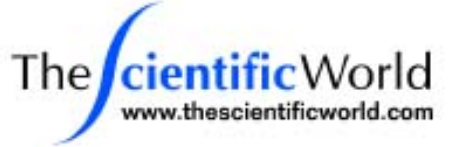

\title{
ENHANCED VASODILATOR RESPONSES TO CGRP (CALCITONIN GENE- RELATED PEPTIDE) IN SUBCUTANEOUS ARTERIES IN HUMAN HYPERTENSION
}

\author{
H. Lind and L. Edvinsson \\ Division of Experimental Vascular Research, Department of Internal Medicin, Lund University \\ Hospital, Lund, Sweden
}

\section{INTRODUCTION}

To evaluate alterations induced by essential and renovascular hypertension on vasomotoresponse to CGRP, substance P, potassium and noradrenaline human subcutaneous vessels were studied. Isolated segments ( 1 to $2 \mathrm{~mm}$ ) of small subcutaneous arteries (diameter 0.1 to $0.9 \mathrm{~mm}$ ) and veins $(0.1$ to $1.0 \mathrm{~mm}$ ) with intact endothelium from patients (essential $n=10$, renovascular $n=6)$ and controls $(n=17)$ were used.

\section{METHODS}

In accordance with our previously published method description[1] cylindrical segments (1 to 2 mm long) were mounted on two L-shaped metal prongs, one of which was connected to a force displacement transducer (FT03C) attached to a PowerLab unit for continuous recording of the isometric tension on a PC computer, and the other to a displacement device.

\section{RESULTS}

Enhanced dilatory responses (Emax) but no change in sensitivity $\left(\mathrm{pEC}_{50}\right)$ were demonstrated in arteries but not in the veins to CGRP in hypertensives $(p<0.01)$ as compared to normotensives, and in the hypertensives subgroups (essential hypertension $p<0.05$; renovascular hypertension $p$ $<0.05$ ). The maximum dilatory response in the arteries of the controls was (Emax \pm s.e.m.) $48.6 \pm$ 8.0\% (see Figure). Corresponding values for hypertensives was $78.7 \pm 5.4 \%$, (subgroups; essential hypertensives $77.2 \pm 7.2 \%$ and renovascular hypertension $82.0 \pm 7.6 \%$ ). The relaxant responses to substance $\mathrm{P}$ were not altered neither in arteries nor veins of the hypertensives. Furthermore, there were no differences in the contractile responses to $60 \mathrm{mM}$ potassium or $10 \mu \mathrm{M}$ noradrenaline between the groups.

\section{CONCLUSION}

The results suggests that the enhanced vasodilator response to CGRP in hypertension is an adaptive reaction. The elevated blood pressure may be augmented by vasodilatory activity since different subgroups of hypertensives showed the same results.

\section{REFERENCE}

1. Högestedt, E.D., Andersson, K.E., and Edvinsson, L. (1983) Mechanical properties of rat cerebral arteries as studied by a sensitive device for recording of mechanical activity in isolated small blood vessels. Acta Physiol. Scand. 117, 4961. 



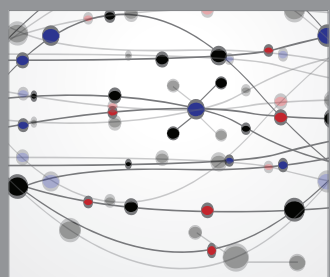

The Scientific World Journal
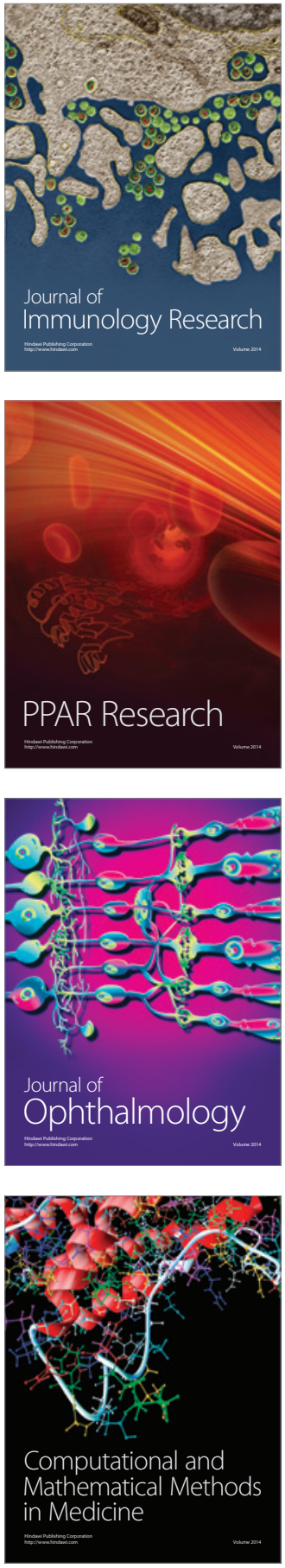

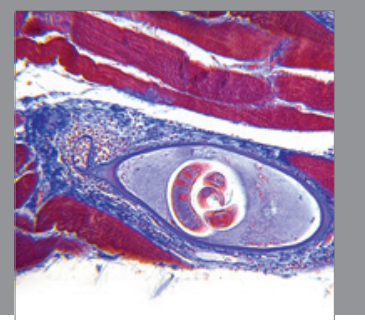

Gastroenterology

Research and Practice
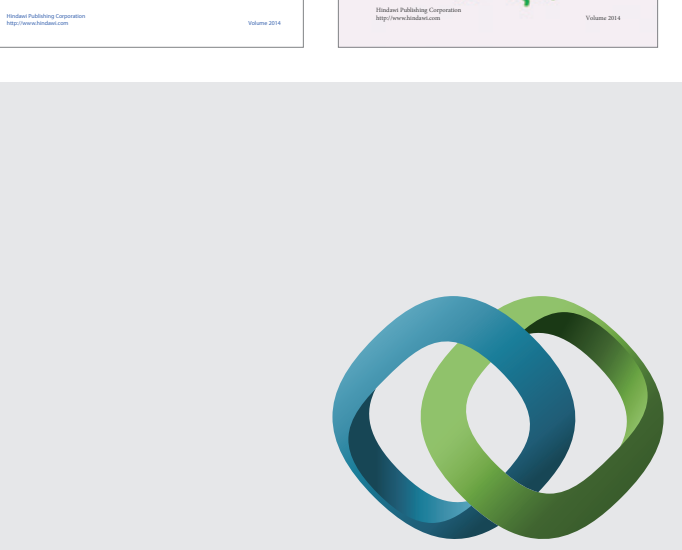

\section{Hindawi}

Submit your manuscripts at

http://www.hindawi.com
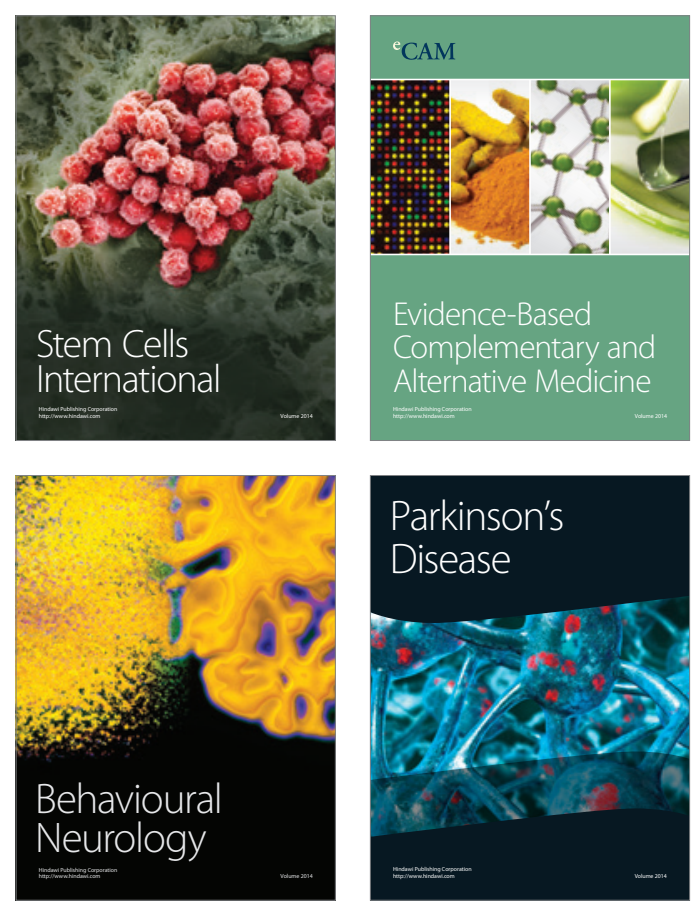

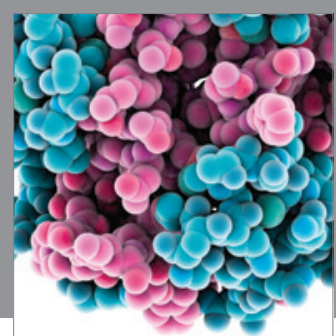

Journal of
Diabetes Research

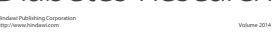

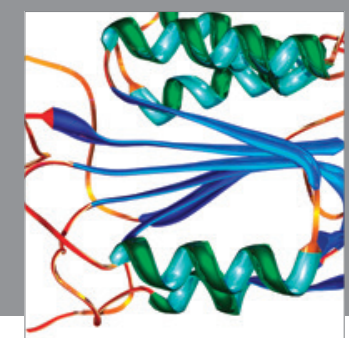

Disease Markers
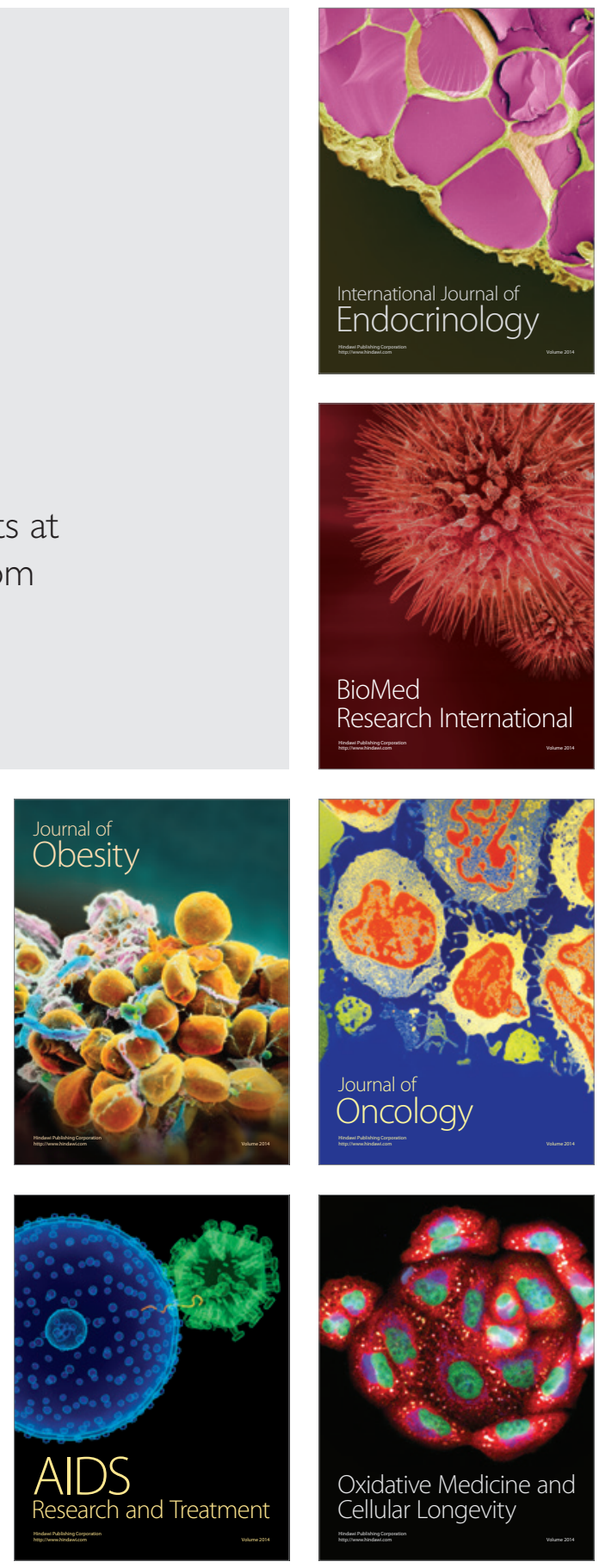